Article

\title{
Extraction of Betulin, Trimyristin, Eugenol and Carnosic Acid Using Water-Organic Solvent Mixtures
}

\section{Fulgentius N. Lugemwa}

Department of Chemistry, Pennsylvania State University-York, 1031 Edgecomb Avenue, York 17403, PA, USA; E-Mail: ful4@psu.edu; Tel.: +1-717-771-8409; Fax: +1-717-771-4062

Received: 12 June 2012; in revised form: 26 July 2012 / Accepted: 27 July 2012 /

Published: 3 August 2012

\begin{abstract}
A solvent system consisting of ethyl acetate, ethyl alcohol and water, in the volume ratio of 4.5:4.5:1, was developed and used to extract, at room temperature, betulin from white birch bark and antioxidants from spices (rosemary, thyme, sage, and oregano) and white oak chips. In addition, under reflux conditions, trimyristin was extracted from nutmeg using the same solvent system, and eugenol from olives was extracted using a mixture of salt water and ethyl acetate. The protocol demonstrates the use of water in organic solvents to extract natural products from plants. Measurement of the free-radical scavenging activity using by 2,2-diphenyl-1-picrylhydrazyl (DPPH) indicated that the extraction of plant material using ethyl acetate, ethyl alcohol and water $(4.5: 4.5: 1, \mathrm{v} / \mathrm{v} / \mathrm{v})$ was exhaustive when carried out at room temperature for $96 \mathrm{~h}$.
\end{abstract}

Keywords: toxic chemicals; liquid extraction; spices; antioxidants

\section{Introduction}

Liquid extraction constitutes a critical step in the isolation of different compounds from terrestrial plants, marine organisms, and cultured broth. The pure compounds isolated from these sources can be used in basic or clinical research. Crude extracts obtained by liquid extraction are often used in cosmetics and food supplement industries or in pest management programs, where their uses are not regulated by the Food and Drug Administration. Solvent extraction has been carried out under different conditions. The raw material can be macerated and suspended in a solvent at room temperature for a few h to several days [1,2]; it can be boiled in organic solvents such as toluene [3]; or, can be directly extracted using a Soxhlet apparatus [4]. After removing the extracting solvent, pure compounds from crude extracts are obtained using different techniques that include various chromatographic methods, 
followed by crystallization, if the compounds are solids. Toxic organic solvents such as dichloromethane, chloroform, benzene, and toluene are frequently used for extracting compounds from different sources in natural products research [3,5-10]. After extraction, these solvents are easily removed under reduced pressure. Sometimes, preferential extraction of the compound of interest can be achieved if a proper solvent is used.

Hot water is also capable of extracting some polar organic compounds from natural products, for example, caffeine, polyphenols and other organic compounds can be extracted from tea and coffee. During the maturation of distilled spirits in wood casks, the ethyl alcohol-water mixture extracts several compounds from the wood during the slow maturation process [11,12]. The wood components that are hydrophobic and have low solubility in aqueous solvent systems include ellagic acid, furfural, vanillin, and syringaldehyde $[13,14]$. These extractions, though not efficient, demonstrate a possibility of using polar solvents to extract non-polar organic compounds, if the extraction conditions are optimized. Such efforts could lead to cheap and more eco-friendly processes that could be applied to various extraction processes, provided the compounds to be extracted are stable under those conditions. In this report, the extraction of organic compounds from plants using a mixture of water, ethyl acetate and ethyl alcohol is reported.

\section{Results and Discussion}

Several bioactive compounds have been derived from betulin, but it is still possible to obtain many other derivatives through rearrangements, ring expansions, ring contractions, and cleavages that provide entry into the triterpene's skeleton to carry out further functionalization. The potential of obtaining new model compounds makes it necessary to come up with new efficient and eco-friendly methods of obtaining large quantities of betulin from sustainable sources. The extraction of betulin from white birch bark has been carried out using different solvents $[3,15,16]$. The skeleton of betulin with the exception of two hydroxyl groups, located far apart at both ends of the molecule (Figure 1), is quite hydrophobic; however, betulin is soluble in acetic acid. We reasoned that a polar solvent system could be used to extract betulin at room temperature, even though previous extractions had been carried out successfully using relatively non-polar solvents like chloroform, dichloromethane and toluene under reflux conditions. In general, the extraction process is affected by solvent polarity, analyte polarity, temperature, and the extraction time. The solvent system consisting of ethyl acetate, ethyl alcohol, and water in the volume ratio of 4.5:4.5:1 was found to be the most efficient, and was obtained by a trial and error method. Extractions were carried out for 12, 24, 48 and $96 \mathrm{~h}$ at room temperature (data not shown). Exhaustive extraction was achieved after $96 \mathrm{~h}$. Mixtures of ethyl acetate, ethanol, and water in other volume ratios were less effective in extracting betulin from white birch bark. The amount of water used could not exceed $10 \%$ because of miscibility problems with the organic solvents. Upon concentrating under vacuum, after extracting the plant material, the crude solid precipitated, as the amount of ethyl acetate and ethanol decreased, which simplified the isolation of the product. More ethyl acetate was added to the aqueous mixture after concentration, the organic layer separated and concentrated to produce a cleaner product that was devoid of the more polar water-soluble components. The total extract consisted of betulin, and lupeol as minor product. The presence of the two compounds was detected by thin layer chromatography using previously isolated 
standards. The recovery obtained after extracting with ethyl acetate and ethanol in the volume ratio of 1:1 was as good the one obtained by using ethyl acetate, ethanol, and water in the volume ratio of 4.5:4.5:1; extracting with either ethyl acetate or ethyl alcohol alone was less efficient (Table 1). Pure betulin from crude extracts was isolated after running a short silica gel column eluting with a mixture of hexane and ethyl acetate, followed by recrystallization from $75 \%$ ethyl alcohol (Table 2 ). After the first extraction, the second extraction of the plant material produced a total mass of material that was less than $1 \%$ of the first extract, indicating that the first extraction removed the majority of the compound. The amount of pure betulin obtained by using ethyl acetate, ethyl alcohol and water was the same as that obtained by using hot toluene. The identity of betulin and lupeol were confirmed using ${ }^{1} \mathrm{H}-\mathrm{NMR}$.

Figure 1. Compounds extracted using a mixture of water, ethyl acetate end ethyl alcohol.

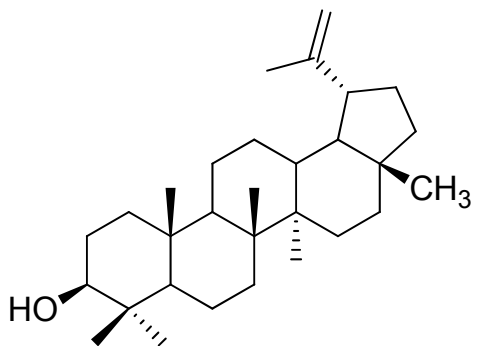

Lupeol

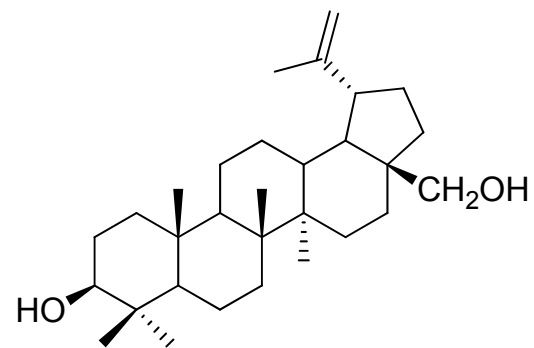

Betulin<smiles>[R]C12CCCC(C)(C)[C@H]1CCc1cc(C(C)C)c(O)c(O)c12</smiles>

Carnosic acid

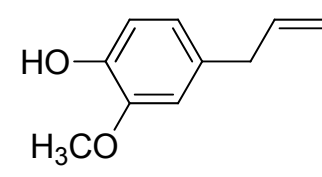

Eugenol

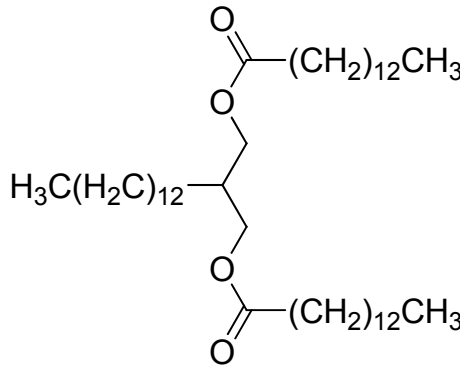

Trimyristin

Table 1. Total extract from $20 \mathrm{~g}$ white birch bark.

\begin{tabular}{cc}
\hline Solvent system & Extract $(\mathbf{g})$ \\
\hline Ethyl acetate:ethanol:water $(4.5: 4.5: 1, \mathrm{v} / \mathrm{v} / \mathrm{v})$ & 4.4 \\
Ethyl acetate and ethanol $(1: 1, \mathrm{v} / \mathrm{v})$ & 4.5 \\
Ethanol & 2.2 \\
Ethyl acetate & 2.5 \\
Ethyl acetate:ethanol:water $(6: 3: 1)$ & 3.7 \\
Ethanol:water $(1: 1)$ & 2.0 \\
\hline
\end{tabular}


Table 2. Pure betulin obtained from $4 \mathrm{~g}$ of white birch bark extract.

\begin{tabular}{cc}
\hline Solvent system & Betulin (g) \\
\hline Ethyl acetate:ethanol:water $(4.5: 4.5: 1, \mathrm{v} / \mathrm{v} / \mathrm{v})$ & 2.8 \\
Ethyl acetate:ethanol $(1: 1, \mathrm{v} / \mathrm{v})$ & 2.2 \\
Hot toluene & 2.7 \\
\hline
\end{tabular}

In order to evaluate the usefulness of the water, ethyl acetate, ethyl alcohol solvent system, the extraction from plants of compounds that have different structures was carried out. The isolation of trimyristin from nutmeg is a popular introductory-level college organic chemistry experiment. Trimyristin is routinely extracted using hot ether or dichloromethane followed by crystallization from acetone. The extraction of trimyristin using ethyl acetate, ethanol and water in the ratio of 4.5:4.5:1, at room temperature was not efficient, but at reflux, an $8.0 \%$ product recovery was achieved without using diethyl ether, dichloromethane or acetone. Crystals of trimyristin formed in the extraction solvent upon cooling, which simplified the isolation of the crude product. The product obtained after washing with a fresh, cold mixture of solvent system similar to the one used for extraction, was deemed pure and recrystallization from acetone was not necessary.

Carnosic acid has been extracted from rosemary by different methods, including supercritical carbon dioxide and super-heated water [17-23]. Using ethyl acetate, ethanol and water in the volume ration of $4.5: 4.5: 1$, the amount of carnosic acid extracted was comparable to that obtained by using other solvents (Table 3).

Table 3. Carnosic acid from rosemary using different extraction methods.

\begin{tabular}{cc}
\hline Solvent & Carnosic acid mg/g \\
\hline Ethyl acetate:ethanol:water & 32.5 \\
Acetone & 26.3 \\
Methanol & 20.5 \\
\hline
\end{tabular}

The isolation of eugenol from cloves was also accomplished without applying dichloromethane. However, like in the case of trimyristin, the extraction solvent conditions were modified. Instead of using a homogeneous mixture of ethyl acetate, ethyl alcohol and water in the volume ration of 4.5:4.5:1, the solvent system was changed. A mixture of 5\% sodium chloride and ethyl acetate was used. The salting-out process enabled the product to accumulate in the organic solvent. After separating the organic layer from the aqueous mixture, followed by concentrating under vacuum, pure eugenol was obtained after using a short silica gel column. The purity was checked by thin layer chromatography.

In order to further test the efficacy of extraction at room temperature without isolating any one pure compound, four spices and white oak wood that contain antioxidants [24,25] were extracted twice, and the radical-scavenging activity of the two different extracts measured by 2,2-diphenyl-1-picrylhydrazyl (DPPH) assay [26]. The total phenolic content of each spice was also determined using the Folin-Ciocalteau assay [27]. In all cases (Table 4), the $\mathrm{LC}_{50}$ in $\mathrm{mg}$ phenol/L of the first extract was more than 20 times that of the second extract, indicating that the first extract removed more than $95 \%$ of the desired compounds. 
Table 4. Extraction effectiveness of ethyl acetate, ethyl alcohol, and water in the volume ratio of $4.5: 4.5: 1$ on spices.

\begin{tabular}{ccc}
\hline Plant & $\begin{array}{c}\text { First extraction } \mathbf{L} \mathbf{C}_{\mathbf{5 0}} \\
(\mathbf{m g} \text { of phenol/L) }\end{array}$ & $\begin{array}{c}\text { Second extraction } \mathbf{L} \mathbf{C}_{\mathbf{5 0}} \\
(\mathbf{m g} \text { of } \mathbf{~ p h e n o l} / \mathbf{L})\end{array}$ \\
\hline Rosemary & 414.0 & $>9409$ \\
Sage & 787.9 & $>16,530$ \\
Thyme & 483.5 & $>10,626$ \\
Oregano & 591.5 & $>12,830$ \\
White oak & 879.5 & $>19,338$ \\
\hline
\end{tabular}

The spices used in this study contain several known antioxidative phenolic compounds with different structures, and the free-radical scavenging assay provided a good method of evaluating the efficiency of the extraction procedure before pure compounds are isolated.

\section{Experimental Section}

Organic solvents and other chemicals were purchased from Sigma Aldrich and used without purification. White oak particles were obtained from Kairos Global, LLC (Shreveport, LA, USA). Spices produced by McCormick ${ }^{\circledR}$ were purchased from grocery stores in southeastern Pennsylvania. White birch bark was obtained from Ontario, Canada. All plant materials were dried in an oven at $80{ }^{\circ} \mathrm{C}$ to constant weight. Melting points were determined using a Melt-Temp apparatus (Laboratory Devices, Cambridge, MA, USA), and are not corrected. The IR spectrum was obtained using a Buck Scientific Model 500 spectrophotometer. Fourier transform NMR spectra were recorded at $400 \mathrm{MHz}$ for ${ }^{1} \mathrm{H}$ on a Bruker DRX 400 spectrometer in $\mathrm{CDCl}_{3}$ at $25^{\circ} \mathrm{C}$.

\subsection{Extraction of Betulin from White Birch Bark}

Ground white birch bark (20.0 g) in ethyl acetate, ethyl alcohol and water in 4.5:4.5:1, volume ratio $(50 \mathrm{~mL})$ was allowed to stand at room temperature for $96 \mathrm{~h}$. Upon concentration under vacuum, a solid precipitated out of solution. Ethyl acetate was added to the mixture and the organic solvent collected and concentrated to yield a solid consisting of two major spots by TLC. Purification of betulin was performed by flash chromatography on silica gel $(30-60 \mu \mathrm{m})$ using a mixture of hexane and ethyl acetate. Lupeol eluted first as a white solid: mp $212-214{ }^{\circ} \mathrm{C}$ (lit. [28], 213-215 ${ }^{\circ} \mathrm{C}$. ${ }^{1} \mathrm{H}-\mathrm{NMR}, \delta 4.6$ (brs, 1H), 4.58 (brs, 1H, 3.30 (dd, $J=4.6,12.0 \mathrm{~Hz}, 1 \mathrm{H}), 2.40-2.34$ (m, 1H0, 1.96-1.90 (m, 1H), 1.70 (s, 3H), 1.67-1.49) m, 10H), 1.43-1.32 (m, 8H), 1.25-1.16 (s, 4H), 1.10-0.90 (m, 1H), 1.05 (s, 3H), $0.99(\mathrm{~s}, 3 \mathrm{H}), 0.97(\mathrm{~s}, 3 \mathrm{H}), 0.84(\mathrm{~s}, 3 \mathrm{H}, 0.79(\mathrm{~s}, 3 \mathrm{H}), 0.75(\mathrm{~s}, 3 \mathrm{H})$. Following lupeol, betulin eluted as a white solid: $\mathrm{mp} 254-255^{\circ} \mathrm{C}$ (lit. [29], 253-254 ${ }^{\circ} \mathrm{C}$ ); IR (KBr), 3400, 3080, 1644, 1449, 1382, 1010, 890; ${ }^{1} \mathrm{H}-\mathrm{NMR}, \delta 4.67$ (m, 1H, 29-H), 4.59 (m, 1H, 29-H), 3.80 (d, 1H, J = 10.20 Hz, 28-H), 3.35 (d, $1 \mathrm{H}, J=10.20 \mathrm{~Hz}, 28-\mathrm{H}) 3.71(\mathrm{~m}, 1 \mathrm{H}, 3-\mathrm{H}), 2.38(\mathrm{~m}, 1 \mathrm{H}, 19-\mathrm{H}), 1.05-2.05$ (complex, $\mathrm{CH}_{2}$ and $\mathrm{CH}), 1.02,0.97,0.97,0.82,0.76\left(\right.$ all s, $\left.15 \mathrm{H}, 5 \mathrm{xCH}_{3}\right)$. 


\subsection{Extraction of Carnosic Acid from Rosemary and Analysis by HPLC}

Finely ground rosemary leaves $(10.0 \mathrm{~g})$ was placed in $100 \mathrm{~mL}$ of ethyl acetate, ethyl alcohol and water in 4.5:4.5:1 volume ratio. After standing at room temperature for $96 \mathrm{~h}$, the mixture was filtered, and a small amount of the total liquid extract analyzed by HPLC using an Aqua C-18-125A $(150 \times 4.0 \mathrm{~mm}, 5$ micron) from Phenomenex (Torrance, CA, USA). The elution was accomplished with a gradient starting at $10 \%$ methanol and $90 \%$ water containing acetic acid $(2.5 \%)$.

\subsection{Extraction of Trimyristin}

Nutmeg $(2.0 \mathrm{~g})$ and three boiling chips were added to $25 \mathrm{~mL}$ of ethyl acetate, ethanol and water in 4.5:4.5:1 volume ratio. The mixture was refluxed gently with occasional shaking. There was minimum bumping during heating. After one hour, the mixture was vacuum filtered while still hot, and the hot solution quickly transferred to a $25 \mathrm{~mL}$ beaker and left at room temperature for the crystals to form. The cold mixture was vacuum filtered, crystals washed with cold ethyl acetate, ethanol and water in 4.5:4.5:1, volume ratio $(5 \mathrm{~mL})$ and dried to obtain $0.16 \mathrm{~g}, 8.0 \%$ recovery, $\mathrm{mp} 56-58{ }^{\circ} \mathrm{C}$.

\subsection{Extraction of Eugenol from Cloves}

Coarsely ground dry cloves $(4.95 \mathrm{~g})$ in a mixture of ethyl acetate $(30 \mathrm{~mL})$ and $5 \%$ sodium chloride solution $(10 \mathrm{~mL})$ were placed in $100 \mathrm{~mL}$ flask and heated at reflux for 1 hour. The hot mixture was filtered; the residue washed with ethyl acetate $(20 \mathrm{~mL})$, and the filtrate placed in a $100 \mathrm{~mL}$ separatory funnel to remove the aqueous layer. After collecting the organic layer, the aqueous layer was back extracted with $10 \mathrm{~mL}$ of ethyl acetate. The combined organic extract was washed with $10 \mathrm{~mL}$ of water and concentrated under vacuum. The resulting oil was dissolved in ethyl acetate $(10 \mathrm{~mL})$ and filtered to remove solid particles. After concentration $0.46 \mathrm{~g}$ of oil was recovered. The product was purified on a short silica gel column using hexane and ethyl acetate as eluent. The extracted product was found to be pure by thin layer chromatography using commercial eugenol as a standard.

\subsection{Extraction of Plant Material for Determining Free-Radical Scavenging Activity and Total}

\section{Phenolic Content}

Crushed plant material (1.0 g) was dissolved in ethyl acetate, ethyl alcohol and water in 4.5:4.5:1 volume ratio $(50 \mathrm{~mL})$. After standing at room temperature for $96 \mathrm{~h}$, the mixture was filtered. The residue was washed with $10 \mathrm{~mL}$ of extracting solvent and filtered. The two solutions were combined and aliquots were used for the DPPH and total phenolic content assays without concentration. The residue was then dried and re-extracted with fresh ethyl acetate, ethyl alcohol and water in 4.5:4.5:1 volume ratio $(50 \mathrm{~mL})$. After $96 \mathrm{~h}$ at room temperature the product was treated as in the first extraction before carrying out the DPPH and the total phenol assays to compare antioxidative activity.

\subsection{Determination of the Free-Radical Scavenging Activity}

The free-radical scavenging activity was measured by the 2,2-diphenyl-1-picrylhydrazyl (DPPH) method described by Blois, with some modification [17]. Different amounts of extract and methanol 
were added to a solution of $0.3 \mathrm{mg} / \mathrm{mL}$ methanolic solution of DPPH to make up a total volume of $3.0 \mathrm{~mL}$. After standing for $30 \mathrm{~min}$ at room temperature, the absorbance was measured at $517 \mathrm{~nm}$ using an SQ-2800 UV/Visible-Cole Palmer Instruments Company (Vernon Hill, IL, USA). High absorbance of the reaction mixture indicated low free radical scavenging activity. The $\mathrm{IC}_{50}$ value, defined as the amount of antioxidant necessary to decrease the initial DPPH concentration by $50 \%$, was estimated from the results using Microsoft Excel. The capability to scavenge the DPPH radical was calculated using the following equation:

$$
\mathrm{I}=\left[\left(\mathrm{OD}_{\mathrm{o}}-\mathrm{OD}_{\mathrm{s}} / \mathrm{OD}_{\mathrm{o}}\right) \times 100\right]
$$

where I was the inhibition percentage; $\mathrm{OD}_{0}$, was the absorbance of the negative control (containing $100 \mu \mathrm{L}$ of $\mathrm{MeOH}$ instead of the sample); and $\mathrm{OD}_{\mathrm{s}}$ was the absorbance of the samples. The experiment was carried out in triplicate and the results are average values.

\subsection{Determination of Total Phenol}

Determination of the amount of phenol as gallic acid equivalent was carried out using Folin-Ciocalteau method with minor modifications. The spice extract $(20 \mu \mathrm{L})$, water $(1.58 \mathrm{~mL})$, Folin-Ciocalteau reagent $(100 \mu \mathrm{L})$ and saturated sodium carbonate solution $(300 \mu \mathrm{L})$ were incubated at $40{ }^{\circ} \mathrm{C}$. After $30 \mathrm{~min}$, optical density was read at $765 \mathrm{~nm}$, and the amount of total phenol calculated using a calibration curve.

\section{Conclusions}

A mixture of ethyl acetate, ethyl alcohol and water in the volume ration of 4.5:4.5:1 was effective in extracting betulin from white birch at room temperature. The amount recovered was similar to that obtained using other solvents like chloroform, dichloromethane and toluene. The solvent system was also efficient in extracting antioxidants from spices. Additionally, eugenol and trimyristin were extracted using a modified solvent system at high temperature. Overall, the relatively eco-friendly solvent system was capable of extracting compounds with different structures at low temperature. This indicates that the system can be used to extract other compounds provided those compounds are stable under the experimental conditions.

\section{Acknowledgments}

The study was supported by Pennsylvania State University-York Smith Fund.

\section{References}

1. Rajab, M.S.; Bentley, M.D.; Alford, A.R.; Mendel, M.J. A new limonoid insect antifeedant from the fruit of Melia volkensii. J. Nat. Prod. 1988, 51, 168-171.

2. Mayer, R. Calycopterones and Calyflorenones, Novel Biflavonoids from Calycopteris floribunda. J. Nat. Prod. 1999, 62, 1274-1278.

3. Green, B.; Bentley, M.B.; Chung, B.Y.; Lynch, N.G.; Jensen, B.L. Allobetulin and its derivatives: Synthesis and biological activity. J. Chem. Educ. 2007, 84, 1985-1987. 
4. Meksuriyen, D.; Cordell, G.A.; Ruangrungsi, N.; Tantivatana, P. Traditional medicinal plants of thailand, IX. 10-Hydroxy-11-methoxydracaenone and 7,10-Dihydroxy-11-methoxydracaenone from Dracaena loureiri. J. Nat. Prod. 1987, 50, 1118-1125.

5. Graber, M.A.; Gerwick, W.H. Antibiotic bisanthraquinones produced by a streptomycete isolated from a cyanobacterium associated with esteinascidia turbinate. J. Nat. Prod. 1998, 61, 677-680.

6. Tchouanken, J.-C.; Nyasse, B.; Tsamo, E. 7a,20(S)-Dihydroxy-4,24(28)-ergostadien-3-one from Entandrophragma utile. J. Nat. Prod. 1996, 59, 958-959.

7. Toki, M.; Ooi, T.; Kusumi, T. Sesterterpenoids and diterpenoids of the wax excreted by a scale insect, Ceroplastes pseudoceriferus. J. Nat. Prod. 1999, 62, 1504-1509.

8. Kikuzaki, H.; Sato, A.; Mayahara, Y.; Nakatani, N. Galloylglucosides from berries of Pimenta dioica. J. Nat. Prod. 2000, 63, 749-752.

9. Sree Rama Murthy, M.; Venkata Rao, E. Comparative toxicity assessment of three Tephrosia species on Artemia salina and animal cell lines. J. Nat. Prod. 1985, 48, 967-968.

10. Guidoin, M.; Yang, J.; Pichette, A.; Roy, C. Betulin isolation from birch bark by vacuum and atmospheric sublimation. A thermogravimetric study. Themochim. Acta 2003, 398, 153-166.

11. Puech, J.-L. Extraction and evolution of lignin products in Armagnac matured in oak. Am. J. Enol. Viticult. 1981, 32, 111-114.

12. Cadahía, E.; Fernández De Simón, B.; Jalocha, J. Volatile compounds in Spanish, French, and American oak woods after natural seasoning and toasting. J. Agric. Food Chem. 2003, 51, 5923-5932.

13. Litchev, V. Changes in the profile of volatile compounds in wines stored under oxygen and their relationship with the browning process. Am. J. Enol. Viticult. 1989, 40, 34-35.

14. Glabasnia, A.; Hofmann, T. Sensory-directed identification of taste-active ellagitannins in American (Quercus Alba L.) and European oak wood (Quercus robur L.) and quantitative analysis in Bourbon whiskey and oak-matured red wines. J. Agric. Food Chem. 2006, 54, 3380-3390.

15. O’Conell, M.M.; Bentley, M.D.; Campbell, C.S.; Cole, B.J.W. Betulin and lupeol in bark from four white-barked birches. Phytochemistry 1988, 27, 2175-2176.

16. Chen, Q.H.; Fu, M.L.; Liu, J.; Zang, H.F.; He, G.Q.; Ruan, H. Optimization of ultrasonic-assisted extraction (UAE) of betulin from white birch bark using response surface methodology. Ultrason. Sonochem. 2009, 16, 599-604.

17. Albu, S.; Joyce, E.; Paniwnyk, L.; Lorimer, J.P.; Mason, T.J. Potential for the use of ultrasound in the extraction of antioxidants from Rosmarinus officinalis for the food and pharmaceutical industry. Ultrason. Sonochem. 2004, 11, 261-265.

18. Nakatani, N. Phenolic Compounds in Food and Their Effects on Health II; Juliani, H.R., Welch, C., Asante-Dartey, J., Acquaye, D., Wang, M., Simon, J.E., Eds.; ACS Symposium Series; American Chemical Society: Washington, DC, USA, 1992; Chapter 6.

19. Tena, M.T.; Valcárcel, M.; Hidalgo, P.J.; Ubera, J.L. Supercritical fluid extraction of natural antioxidants from rosemary: Comparison with liquid solvent sonication. Anal. Chem. 1997, 69, 521-526.

20. Basile, A.; Jimnez-Carmona, M.M.; Clifford, A.A. Extraction of rosemary by superheated water. J. Agric. Food Chem. 1998, 46, 5205-5209.

21. Hidalgo, P.J.; Ubera, J.L.; Tena, M.T.; Valcárcel, M. Determination of the carnosic acid content in wild and cultivated Rosmarinus officinalis. J. Agric. Food Chem. 1998, 46, 2624-2627. 
22. Ibáñez, E.; Oca, A.; de Murga, G.; López-Sebastián, S.; Tabera, J.; Reglero, G. Supercritical fluid extraction and fractionation of different preprocessed Rosemary plants J. Agric. Food Chem. 1999, 47, 1400-1404.

23. Ibáñez, E.; Kubotova, A.; Senorans, F.J.; Cavero, S.; Reglero, G.; Hawthorne, S.B. Subcritical water extraction of antioxidant compounds from rosemary plants. J. Agric. Food Chem. 2003, 51, $375-382$.

24. Miura, K.; Kikuzaki, H.; Nakatani, N. Antioxidant activity of chemical components from Sage (Salvia officinalis L.) and Thyme (Thymus vulgaris L.) measured by the oil stability index method. J. Agric. Food Chem. 2002, 50, 1845-1851.

25. Milos, M.; Mastelic, J.; Jerkovic, I. Chemical composition and antioxidant effect of glycosidically bound volatile compounds from oregano (Origanum vulgare L. ssp. hirtum). Food Chem. 2000, 71, 79-83.

26. Blois, M.S. Antioxidant determination by use of a stable free radical. Nature 1958, 181, 1199-1200.

27. Folin, O.; Ciocalteu, V. On tyrosine and tryptophane determination in proteins. J. Biol. Chem. 1927, 73, 627-650.

28. Lewis, K.G. Triterpene constituents of fruits of Osage orange, Maclura pomifera. J. Chem. Soc. 1959, 73-75.

29. Postovskn, I.Ya. Structure of betulin. J. Russ. Phys.-Chem. Soc. 1930, 62, 101-109.

Sample Availability: Samples of the compounds are available from the authors.

(C) 2012 by the authors; licensee MDPI, Basel, Switzerland. This article is an open access article distributed under the terms and conditions of the Creative Commons Attribution license (http://creativecommons.org/licenses/by/3.0/). 